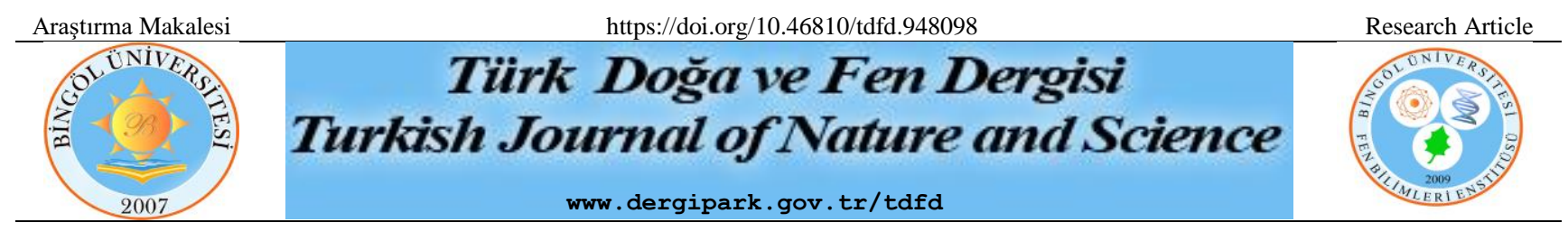

\title{
Derin Transfer Öğrenimi Yaklaşımı ile Kamusal Alanda Medikal Maske Kullanımının Otomatik Kontrolü
}

\author{
Hasan POLAT ${ }^{*}$, Mehmet Siraç ÖZERDEM² \\ ${ }^{1}$ Bingöl Üniversitesi, Teknik Bilimler Meslek Yüksekokulu, Elektrik ve Enerji Bölümü, Bingöl, Türkiye \\ ${ }^{2}$ Dicle Üniversitesi, Mühendislik Fakültesi, Elektrik-Elektronik Mühendisliği Bölümü, Diyarbakır, Türkiye \\ Hasan POLAT ORCID No: 0000-0001-5535-4832 \\ Mehmet Siraç ÖZERDEM ORCID No: 0000-0002-9368-8902
}

*Sorumlu yazar: hasanpolat@bingol.edu.tr

(Alınış: 04.06.2021, Kabul: 10.07.2021, Online Yayınlanma: 31.12.2021)

\begin{abstract}
Anahtar
Kelimeler

Transfer

öğrenimi,

Derin

öğrenme,

SqueezeNet,

Sinıflandirma,

Görüntü işleme,

COVID-19

Öz: Uluslararası kamu sağlığı acil durumu olan COVID-19 hastalığının başlıca bulaşma yolları, solunum damlacıkları ve fiziksel temastır. Hastalığın yayılımını önlemek ve salgınla mücadele etmenin kapsamlı stratejilerinden biri olarak kamusal alanda medikal maske kullanımı birçok toplumda zorunlu kılınmıştır. Bu kapsamda, kamusal alanda medikal maske kullanımının otomatik olarak kontrolü, salgınla mücadelede önem arz etmektedir. Bu çalışmada, transfer öğrenimi yaklaşımı ile kamusal alandan alınan görüntülerden medikal maske kullanımının otomatik olarak tespit edilmesi amaçlanmıştır. Derin mimariye transfer öğrenimi yaklaşımı uygulanarak, öğrenilmiş parametrelerinin ince ayarı ile medikal maske tespitinde etkili çözümlerin elde edilmesi amaçlanmıştır. Medikal maske kullanımının otomatik olarak tespitinde, Human in the Loop (HITL) tarafından erişime açık olarak sunulan görüntüler kullanılmıştır. SqueezeNet tabanlı transfer öğrenimi yaklaşımı ile \%99,20 oranında sınıflandırma doğruluğu elde edilmiştir. ROC eğrisi altında kalan alanın (AUC) büyüklüğü ise 0,998 olarak elde edilmiştir. Ayrıca, transfer öğrenimi yaklaşımının üstünlüğünü vurgulamak için eğitilmiş parametre içermeyen SqueezeNet mimarisi de aynı veri seti üzerinde uygulanmış ve elde edilen performans değerleri karşılaştırılmıştır. Sınırlı sayıda görüntü veri kümesi üzerinde eğitilen mimari ile sınıflandırma doğruluğu ve AUC performansları sırasıyla \%94,75 ve 0,976 olarak elde edilmiştir. Transfer öğrenimi yaklaşımı ile çok kısa sürede eğitilen derin mimarinin medikal maske kullanımı tespitinde etkileyici bir performans sergilediği gözlemlenmiştir.
\end{abstract}

\section{Automatic Control of Using Medical Mask in Public Space by Deep Transfer Learning Approach}

Keywords
Transfer
learning,
Deep
learning,
SqueezeNet,
Classification,
Image
processing,
COVID-19

\begin{abstract}
The main transmission routes of COVID-19, an international public health emergency, are respiratory droplets and physical contact. As one of the comprehensive strategies to prevent and fight against disease the outbreak, the use of medical masks in the public sphere has been made mandatory in many societies. In this context, automatic control of the use of medical masks in the public sphere is crucial in the fight against the outbreak. This study aimed to detect the use of medical masks automatically from images of the public sphere by the transfer learning approach. By transfer learning approach to deep architecture, it is aimed to obtain effective solutions in medical mask detection with fine-tuning of pre-trained parameters. The image data set offered by Human in the Loop (HITL) as open access was used for the automatic detection of medical masks. The SqueezeNet based on transfer learning approach proposed in this study achieved a classification accuracy of $99.20 \%$. In addition, the AUC (area under the ROC curve) value was found as 0.998. To emphasize the superiority of the transfer learning approach, the SqueezeNet architecture, which does not contain trained parameters, was also applied to the same data set and the obtained performance metrics were compared. The model trained from scratch on a limited number of image dataset offered classification accuracy and AUC performances as $94.75 \%$ and 0.976, respectively. As a result, it has been observed that the deep architecture, which has been trained in a very short time with the transfer learning approach, has an impressive performance in detecting the use of medical masks.
\end{abstract}




\section{GíRIŞ}

2019'un Aralık sonlarında, SARS-CoV ailesine mensup mutasyona uğramış yeni tip bir koronavirüs ilk olarak Çin'in Wuhan Şehri, Hubei bölgesinde bir grup bilinmeyen pnömoni olarak rapor edilmiştir [1, 2]. Şiddetli akut solunum sendromuna yol açan bu yeni bilimeyen virüsün gen diziliminin $\% 70$ oranında SARS$\mathrm{CoV}$ virüsüne benzerlik gösterdiği tespit edilmiş ve uluslararası virüs taksonomi komitesi (ICTV) tarafindan SARS-CoV-2 olarak adlandırılmıştır [3]. Hastalarla etkileşim içinde olan sağlık çalışanları ve ailelerinde aynı semptomların görülmesi, SARS-CoV-2'nin insandan insana bulaşabilme kabiliyeti olduğunu ortaya çıkarmıştır. Kısa süre zarfında Çin'in farklı bölgelerine yayılan virüs, birkaç hafta içinde kıtalar arası bir yayılım göstermiştir. İnsanlık tarihinde eşine az rastlanır bir hızla yayılım gösteren bu salgın, Dünya sağlık örgütü (DSÖ) tarafindan 11 Şubat 2020'de pandemi olarak ilan edilmiş ve yeni koronavirüs hastalığı 2019 (COVID-19) olarak adlandırılmıştır. DSÖ tarafından 24 Mayıs 2021 tarihi itibariyle dünya genelinde yaklaşı 167 milyon pozitif vaka olduğu doğrulanmıştır. Ne yazık ki pozitif vakalardan yaklaşık 3,5 milyonu ölümle sonuçlanmıştır [4]. Pozitif vaka sayısındaki olağanüstü artış hızı, hastalığın bulaşma yolları üzerinde durulması gerektiği ve yayılım hızını yavaşlatacak yöntemlerin geliştirilmesi hususunda önem arz etmektedir.

COVID-19 salgını özellikle solunum damlacıkları ve yakın temas ile insandan insana bulaşmaktadır [5]. Kamu yetkilileri COVID-19'la mücadelede, hastalığın bulaşıcılık özelliğinin baskın olması ile birlikte geniş kitlelere çok kısa bir sürede yayılmasını önlemek adına çeşitli önlemler almaktadır. Kamu sağlığında ve ekonomik faaliyetlerinde hastalığın zararlı etkilerinden kurtulmak için acil eylem planları uygulanmaktadır. Bu kapsamda, DSÖ virüsün yayılımına karşı et etkili yöntemlerden birinin medikal maske kullanımı olduğu vurgulamıştır. İnsanların kamusal alanda maske kullanmaları için yeni kararlar alınmakta ve kullanmamaları durumunda çeşitli caydırıcı yaptırımlar uygulanmaktadır. Söz konusu önlemler ile hastalığının yayılımı engellenerek, yeni vaka ve ölüm sayılarındaki üstel artışın önlenmesi amaçlanmaktadır. Ancak, bütün nüfusun kontrol edilmesi oldukça zorlu bir süreçtir. Bu zorlu sürecin üstesinden insan gücü ile gelinmesi, devasa iş gücü ve yeterli personel gereksinimi gibi faktörler dikkate alındığında olanaksız görünmektedir. Dolayısıyla, insanların kamusal alanda medikal maske kullanmalarını yüksek hı ve doğrulukla kontrol edebilecek bilgisayar tabanlı modellerin geliştirilmesi önem arz etmektedir.

Derin öğrenme algoritmalarının biyomedikal görüntülerden çeşitli hastalıkların tespitinde sağlamış olduğu üstün başarı, araştırmacıları COVID-19 ile mücadelede derin öğrenme tabanlı yardımcı sistemlerin geliştirilmesi yönünde motive etmiştir. Bu kapsamda, çoğunlukla hekimlere destek sağlayan yapay zeka tabanlı otomatik tanı modelleri geliştirilmiştir [6-8]. Bu çalışmalarda, bilgisayarlı tomografi (BT) veya X-ray görüntülerinden COVID-19 pnömoni kaynaklı lezyonların ve hastalıkla birlikte lezyonlarda meydana gelen değişimlerin bilgisayar destekli sistemlerce otomatik olarak tespit edilmesi amaçlanmıştır. Hastalığın erken tanısında geliştirilen modellerin yanı sıra bilgisayarlı görü tabanlı sistemlerce maske kullanımın kontrolü ve toplumun alınan kurallara göstermiş olduğu adaptasyonun denetlenmesi, salgınla mücadelede kilit rol oynamaktadır [9]. Dolayısıyla, kısa süre zarfinda medikal maske tespit modellerine ilişkin yapılan çalışmalar dikkat çekmektedir. Bu kapsamda, Khandelwal et al. [10] medikal maske kullanımına ilişkin ikili görüntü sınıflandırma problemi için bir derin öğrenme modeli önermişlerdir. Çalışmalarında, MobileNet v2 modeli kullanarak 380'i maskeli ve 460'1 maskesiz olmak üzere görüntü kümesi kullanmışlardır. Qin et al. [11] maske kullanımı tespitinde süper çözünürlüklü yerleştirilmiş sınıflandırma ağları kullanan bir model önermişlerdir. Önerilen model maskeli, maskesiz ve yanlış maske kullanan olmak üzere üç sınıflı bir problem için geliştirilmiştir. Loey et al. [5] medikal maske tanımada derin öğrenme ve konvansiyonel yönteme dayanan bir hibrit model önermişlerdir. Derin öğrenme mimarilerden ResNet50 modeli uygulanarak özellik çıkarımı yapılmış ve çıkarılan özellikler destek vektör makinesi (DVM) algoritması ile sınıflandırılmıştır. Rao vd. (2020) maske tespitinde her biri 100 filtreden oluşan iki evrişim katmanlı ESA modeli önermişlerdir. Önerilen ağ yapısına ilişkin hiper parametre seçimi ile \%91,21 oranında sınıflandırma doğruluğu elde edilmiştir. Literatürde derin öğrenme veya konvansiyonel yöntemlere dayalı medikal maske kullanımın kontrol edildiği çalışmaların yapıldığı görülebilmektedir. Derin öğrenme modellerinin özellikle görüntülerde nesne tanımadaki güçlü alt yapısı bu alanda da etkinliğini göstermektedir.

$\mathrm{Bu}$ çalışmada, transfer öğrenimi yaklaşımı uygulanarak derin öğrenme tabanlı bir medikal maske tanıma sistemi önerilmiştir. Önerilen modelin mevcut gözetim kameralarına entegre edilmesi ile kamusal alanda medikal maske kullanımı otomatik olarak kontrol edilebilir. Bu kapsamda, gerçek zamanlı uygulamalar için daha az parametre ve depolama alanı gibi sağladığg avantajlar nedeniyle SqueezeNet derin mimarisi kullanılmıştır. Derin mimariye transfer öğrenimi yaklaşımı uygulanarak, önceden eğitilmiş optimize parametrelerinin ince ayarı ile medikal maske tespitinde etkili çözümlerin elde edilmesi amaçlanmıştır. Çalışmada medikal maske tanımada önerilen modelinin etkinliğinin incelenmesi yanı sıra transfer öğrenimi yaklaşımı uygulanmayan ve sıfırdan eğitilen yeni mimariye ilişkin elde edilen performansla da kıyaslanmıştır. Böylelikle, transfer öğrenimi yaklaşımının üstün yönleri vurgulanmaya çalışılmıştır.

Çalışmanın geri kalan kısmı; kullanılan veri seti, uygulanan yöntemler, elde edilen bulgular, bulgular doğrultusunda tartışma ve sonuç bölümlerinden oluşmaktadır. 


\section{MATERYAL VE METOT}

\subsection{Kullanılan Veri Seti}

Bu çalışmada, Human in the Loop (HITL) tarafindan erişime açık olarak sunulan görüntüler kullanılmıştır [12]. HITL tarafindan medikal maske veri seti olarak adlandırılan görüntü kümesi, COVID-19'a karşı dünya çapında mücadeleye katkı sağlamak için olușturulmuștur. Medikal maske veri kümesinde; tüm etnik kökenlerden, yaşlardan ve coğrafyalardan alınan insan görüntüleri bulunmaktadır. Böylelikle, kapsamlı ve güvenilir bilgisayar destekli sistemlerinin geliștirilmesine olanak tanınmıștır. Veri setinin oluşturulmasında çeşitliliğe özen gösterilmesi, 6 bin üzerinde görüntünün toplanmasını sağlamıştır. Veri çeşitliliğinin ve sayısının fazla olması, önerilecek makine öğrenimi modellerinin verimli bir șekilde eğitimlerinin gerçekleşmesini mümkün kılabilmektedir. Şekil 1'de medikal veri setine ilişkin bazı örnek görüntüler gösterilmektedir.
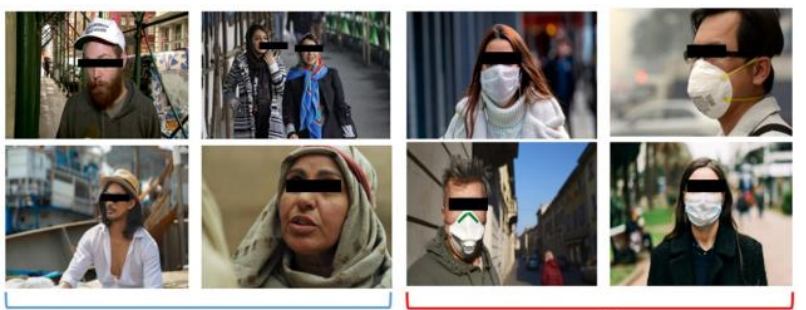

Şekil 1. Medikal maske veri setine ilişkin örnek görüntüler (a): maskesiz insanlar, (b): maske kullanan insanlar

\section{2. Ön İşleme}

$\mathrm{Bu}$ çalışmada, maske kullanımının otomatik olarak tespiti için öncelikle sadece insan yüzlerinin bulunduğu görüntü bölütleri veri setinden kırpılmıştır. Böylelikle, görüntülerde yer alan çeşitli objelere ilişkin gereksiz görüntüler sınıflandırma dișında tutulmuştur. Şekil 2'de medikal maske veri kümesinde yer alan bazı görüntüler için otomatik olarak insan yüzlerinin tespit edilmesi gösterilmektedir.
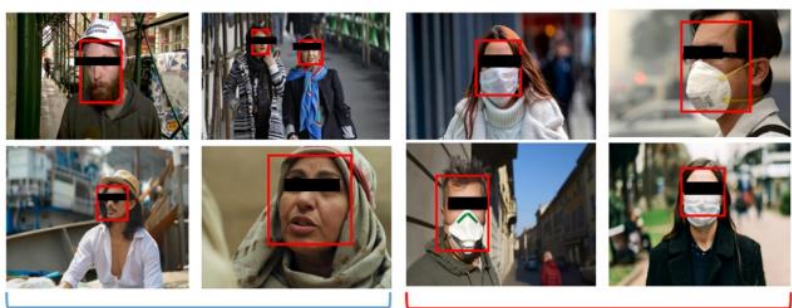

Şekil 2. Medikal maske veri setine ilişkin örnek görüntülerde insan yüzlerinin tespiti

Veri setinde yer alan görüntülerden insan yüzleri tespit edilerek, Matlab programlama ortamında kırpılmıștır. İnsan yüzlerinin kamusal alandan alınan görüntülerden ayrıştırılmasında, Matlab bilgisayarla görme araç kutusunda tanımlanan kademeli nesne tarayıcı fonksiyonu uygulanmıştır. Böylelikle, sadece insan yüzlerinin yer aldığı yeni bir veri seti oluşturulmuştur. Medikal maske veri setinde yer alan orijinal görüntülere ilişkin boyut, poz açısı ve derinlik farklılıkları oluşturulan yeni veri setinde yer alan görüntülerin de farklı boyutlarda olmasına yol açmıştır. Önerilen ESA modelinin etkin bir şekilde kullanımı için veri setini oluşturan görüntüler aynı boyutlarda olması gerekmektedir. Sadece insan yüzlerine ilişkin görüntülerden oluşan veri seti, yeniden boyutlandırılma işlemine tabi tutularak her biri $227 \times 227$ boyutuna dönüştürülmüştür. Sadece insan yüzü görüntülerinden oluşan yeni veri setine ilişkin bazı örnekler Şekil 3'te gösterilmektedir.

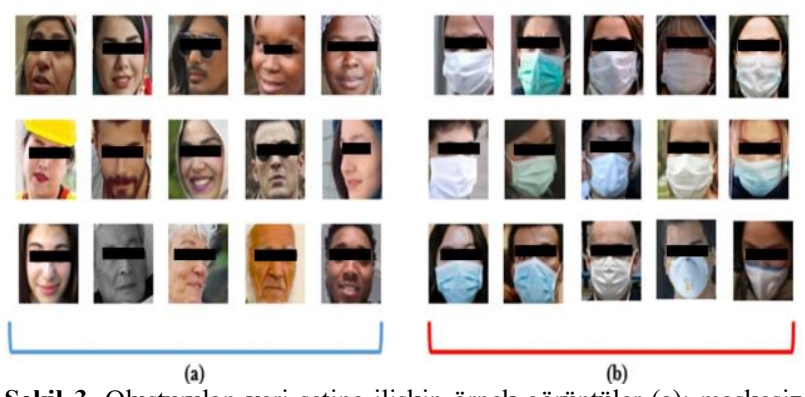

Şekil 3. Oluşturulan veri setine ilişkin örnek görüntüler (a): maskesiz (b): maskeli

Oluşturulan yeni veri setinden 1000 adet maskesiz ve 1000 adet ise maskeli olmak üzere toplamda 2000 görüntü değerlendirmeye alınmıştır.

\subsection{Evrișimsel Sinir Ağları}

ESA algoritmaları, görüntü işleme üzerinde sağladığı üstün performans ile dikkat çeken popüler bir makine öğrenme tekniğidir [13]. Eğitilmiş çok sayıda katman içeren ESA algoritmaları, görsel bilgilerin işlenmesinden sorumlu olan görsel korteksten esinlenerek geliştirilmiştir [14, 15]. Evrişimsel filtreleme tekniği ile görüntü verileri gibi çok boyutlu girişler için ağda kullanılan düğüm ve parametre maliyeti düşürülmektedir. ESA algoritmaları temel olarak özellik çıkarıcı ve sinıflandırıcı katmanlardan meydana gelmektedir. Söz konusu katmanlardan oluşan hiyerarşik yapı, basitten karmaşığa doğru ilerleyerek uçtan uca öğrenimin gerçekleşmektedir. İlk olarak, ağın girișine verilen görüntüyü her katmanda ağırlıklar ve bias değeri cinsinden ifade edilmesi amaçlanır. İkinci aşamada ise zincir kuralına göre her bir parametrenin gradyan değerleri hesaplanır. Sonrasında bütün parametreler gradyan değerlerine göre güncellenir. Her bir ağırlık ve bias değerlerinin güncellenmesi sırasıyla eşitlik 1 ve 2'de ifade dilmiștir.

$$
\begin{gathered}
\Delta W_{l}(t+1)=-\frac{x \lambda}{r} W_{l}-\frac{x}{n} \frac{\partial C}{\partial W_{l}}+m \Delta W_{l}(t) \\
\Delta B_{l}(t+1)=-\frac{x}{n} \frac{\partial C}{\partial B_{l}}+m \Delta B_{l}(t)
\end{gathered}
$$

ESA algoritmasında nihai çıkıș için karar alma süreci, yapay sinir ağına benzerdir. Burada, $\mathrm{W}, \mathrm{B}, 1, \lambda, \mathrm{x}, \mathrm{n}, \mathrm{m}, \mathrm{t}$ ve C sırasıyla ağırlık, bias, katman sayısı, ayarlama parametresi, öğrenme katsayısı, eğitim örneklerinin 


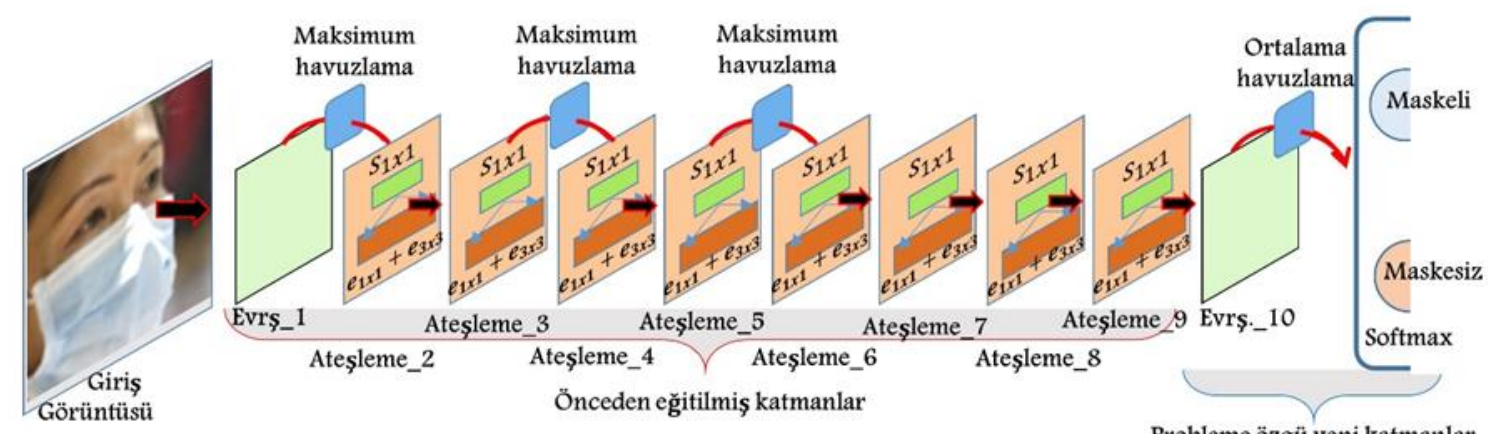

Probleme özgü yeni katmanlar

Şekil 5. Medikal maske tespitinde kullanılan transfer öğreniminin uygulandığg SqueezeNet modeli

toplam sayısı, momentum katsayısı, güncelleme adımı ve maliyet fonksiyonunu temsil etmektedir [16].

Bir ESA mimarisi genel olarak evrişim, havuzlama ve tam bağlı katmandan oluşur. Çeşitli işlem birimleri ve topolojik farklılıkları barındıran güncel mimariler tasarlanarak, spesifik problemler için etkili çözümler sunan ESA modelleri üretilmiştir. $\mathrm{Bu}$ çalışmada, belirlenen hedefler ve sağladığı avantajlar doğrultusunda SqueezeNet modeli kullanılmıştır.

\subsection{SqueezeNet Modeli}

Görüntü işleme üzerinde popüler olan ESA algoritmalarına ilişkin sınıflandırma ve ağ doğruluğunun arttırılması için yeni modeller geliştirilmeye çalışılmıştır. Iandola et al. [17] tarafindan bu amaçların dişında görüntü işleme problemlerinde büyük boyutlu derin mimariler ile sağlanan asgari başarıdan ödün vermeden küçük boyutlu alternatif bir mimari geliştirilmiştir [18]. $\mathrm{Bu}$ kapsamda, AlexNet mimarisine kiyasla 50 kat daha az parametrenin kullanıldığı ve aynı seviyede doğruluk sunan SqueezeNet modeli geliştirilmiştir. Ayrıca, model sıkıştırma teknikleri uygulanarak mimarinin boyutu $0.5 \mathrm{MB}$ 'den küçük daha bir bellek kapasitesinde tutulmuştur. Eğitim sırasında daha az iletişim gereksinimi, daha küçük bant genişliği ve sınırlı depolama alanına sahip donanımlara entegre edilebilme özelliklerine sahip olması SqueezeNet modelinin popülaritesini artırmıştır. $\mathrm{Bu}$ çalışmada, elektronik gözetleme noktalarına entegre edilebilecek bir modelin tasarlanması için sahip olduğu boyutsal avantajlar dikkate alındığında SqueezeNet mimarisinin kullanılması uygun bulunmuştur.

SqueezeNet mimarisinin temeli önerilen ateşleme modüllerinden oluşmaktadır. Bir ateşleme modülü; sıkıştırılmış ve genişletilmiş evrişim katmanlarından oluşur. Sıkıştırılmış katman 1x1 boyutunda filtreleri $\left(s_{1 \times 1}\right)$, genişletilmiş katman ise $1 \times 1\left(e_{1 \times 1}\right)$ ve $3 \times 3\left(e_{3 \times 3}\right)$ boyutunda filtreleri içerir. Sıkıştırılmış katmanda kullanılan filtre sayısı, genişletilmiş katmanda kullanılan toplam filtre sayısında az olarak ayarlanmıştır $\left(\operatorname{num}\left[\left(s_{1 \times 1}\right)\right]<\operatorname{num}\left[\left(\left(e_{1 \times 1}\right)+\left(e_{3 \times 3}\right)\right)\right]\right)$. Şekil 4'te önerilen ateşleme modülü gösterilmektedir.

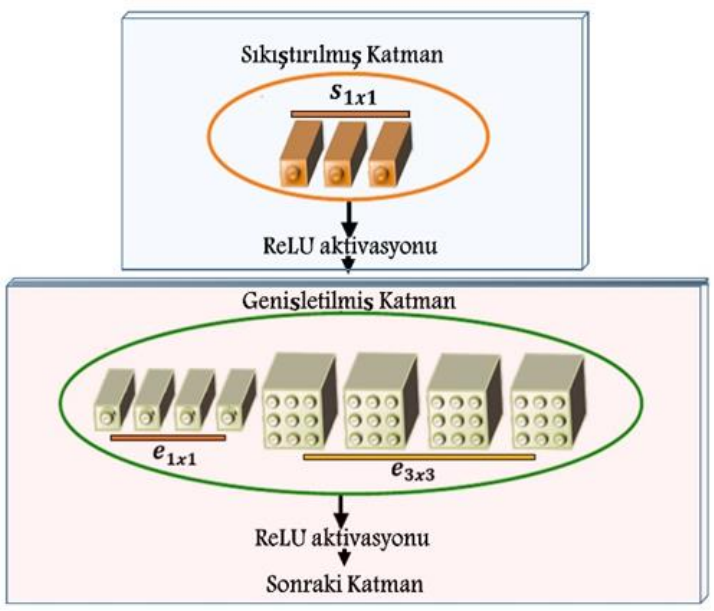

Şekil 4. Ateşleme modülündeki evrişim filtreleri: Bu örnekte; $s_{1 x 1}=3$, $e_{1 \times 1}=4$ ve $e_{3 \times 3}=4$ olarak ayarlanmıştır [17].

Sıkıştırılmış katmandaki 1x1 boyutundaki filtre sayısının genişletilmiş katmanda kullanılan filtre sayısından daha az olması ile giriş kanal sayısının $3 \times 3$ filtrelere sınırlandırılması gerçekleştirilmektedir.

\subsection{Transfer Öğrenimi}

Transfer öğrenimi yaklaşımı ile özellikle derin ağların eğitiminde yeteri sayıda verinin olmadığ önceden eğitilmiş parametrelerin transferi ile spesifik problemler için etkili çözümler sağlanabilir. Belirli bir görev için eğitilen derin yapıların bazı modifikasyonlarla ilişkili başka bir görev için yeniden düzenlenmesi gerçekleşebilir. Dolayısıyla derin bir modelin sil baştan eğitimi için yeterince örneğin olmadığı durumda, transfer öğrenimi kullanışlı bir alternatif yaklaşımdır [18]. Transfer öğrenimi ile ağda yer alan parametreler uygun başlangıç değerleri ile eğitime başlar ve küçük modifikasyonlarla yeni probleme adapte edilirler. Ayrica, parametrelerin ince ayarlanması ile kabul edilebilir bir başarı, daha kısa bir eğitime gereksinim duyacaktır [19]. Bu çalışmada, sınırlı sayıda görüntü verisi için transfer öğrenimi yaklaşımı SqueezeNet modeli üzerinde uygulanmıştır. Şekil 5'te medikal maske tespitinde kullanılan transfer öğreniminin uygulandığ SqueezeNet modeli gösterilmektedir.

Birçok ağda son eğitilebilir katman tam bağlı katman iken SqueezeNet mimarisinde ise farklı olarak evişimsel katman bulunur. Son evrişim katmanı ve sınıflandırıcı 
katman giriş görüntülerinin sınıflandırılmasında kullanılırlar. Önceden eğitilmiş SqueezeNet yeniden eğitmek için bu son iki katman medikal maske görüntü kümesine göre güncelleştirilerek, probleme özgü etkili çözümler elde edilmesi amaçlanmıştır.

\section{6. Önerilen Modelin Eğitim ve Testi}

Kamusal alanda maske kullanımının otomatik olarak tespitinde önerilen modelin sinıflandırılmasında ön işleme akabinde elde edilen yeni görüntü verileri beş eşit eşit alt kümeye bölünmüştür. Alt kümelerden dördü eğitim, kalan biri ise test için kullanılmıştır. Ayrıca ağın öğrenme aşamasında daha iyi bir genelleştirme yapabilmesi için eğitim için ayrılan alt kümelerin $\% 25$ 'i doğrulama (validation) verisi için kullanılmıştır. Medikal maske tespitinde uygulanan sınıflandırma işleminin güvenirliği için beș katlı çapraz doğrulama (five-fold cross-validation) uygulanmıştır.

Bu çalışmada önerilen modelin 50 tekrar (epoch) ile ince ayarlanması yapılmaya çalışılmıştır. ADAM aktivasyon fonksiyonu iyileştirici olarak kullanılmıştır. Başlangıç öğrenme katsayısı ise 0.0001 olarak ayarlanmış ve her bir iterasyondaki görüntü sayısı (mini bacth) ise 64 olarak belirlenmiştir.

\subsection{Model Başarım Metrikleri}

Farklı problemlere özgü geliştirilen sınıflandırma modellerine ilişkin performans değerlendirmesinde kullanılan farklı metrikler mevcuttur. $\mathrm{Bu}$ çalışmada önerilen modelin medikal maske kullanımı tespit etmedeki başarısı model başarım ölçütlerinden olan sınıflandırma doğruluğu, duyarlılık, özgüllük, kesinlik ve F1-skor türünden değerlendirilmeye çalışılmıştır. Ayrıca tüm sınıflandırma eşiklerinde sergilenen performansın değerlendirilmesi için söz konusu metriklere ilave olarak ROC eğri analizi yapılarak, AUC değerleri hesaplanmıştır.

\section{BULGULAR}

$\mathrm{Bu}$ çalışmada transfer öğrenimi yaklaşımı tabanlı önerilen medikal maske kontrol modeli ve ön işleme adımlarının tümü 8GB RAM, intel core i5-2500 3.30 Ghz işlemci ve NVIDIA Geforce ROG-STRIX 256 bit 8GB ekran kartı donanımı üzerinde kurulan Matlab (MathWorks, Natick, MA, USA) programlama ortamında uygulanmıştır. Transfer öğrenimi yaklaşımı ile elde edilen bulgular ve eğitilmiş parametre içermeyen SqueezeNet mimarisi ile elde edilen bulgular ayrı bir şekilde paylaşılmıştır. Böylelikle, transfer öğrenimi yaklaşımının üstünlüğünün nicel olarak değerlendirilmesi sağlanmaya çalışılmıştır.

SqueezeNet modeli üzerinde uygulanan transfer öğrenimi yaklaşımı elde edilen sınıflandırma performansın değerlendirilmesi için test karışıklık matrisleri kullanılmıştır. Test karışıklık matrisleri, bir sinıflandırıcı modelin performansinın değerlendirilmesinde kullanılan popüler bir yöntemdir.
Medikal maske kullanan ve kullanmayan olmak üzere ikili sınıflandırma problemi için model tarafından atanan doğru veya yanlış örnek sayıları değerlendirilebilir. Böylelikle, literatürde popüler olan model başarım ölçütleri hesaplanabilir. Transfer öğrenimi yaklaşımı uygulanarak elde edilen sınıflandırma sonuçlarına ilişkin test karışık matrisleri şekil 6'da verilmektedir.

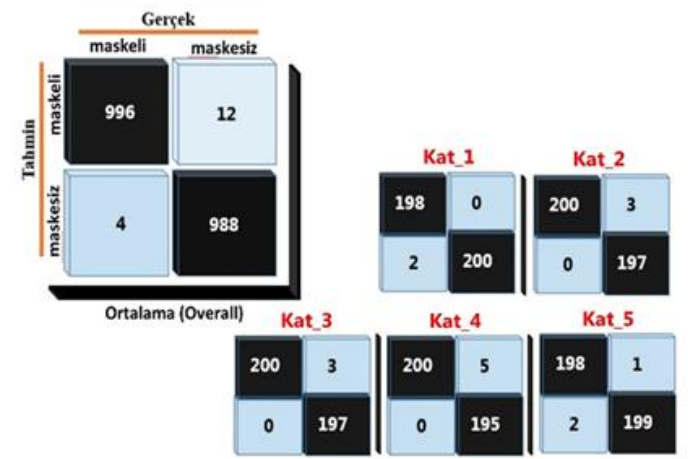

Şekil 6. Transfer öğrenimi yaklaşımına ilişkin test karışıklık matrisi

Önerilen modelin performansı, sıklıkla kullanılan model başarım ölçütleri dikkate alınarak değerlendirilmiştir. Sinıflandirma sürecinde uygulanan beş katlı çapraz doğrulama için her kata (fold) ilişkin sonuçlar ve ortalama sonuçlar tablo 1'de verilmektedir.

Tablo 1. Transfer öğrenimi yaklaşımına ilişkin model başarım metrikleri

\begin{tabular}{lrccccc}
\multicolumn{1}{c}{$\%$} & Kat1 & Kat 2 & Kat 3 & Kat 4 & Kat 5 & Ortalama \\
\hline Doruluk & 99,50 & 99,25 & 99,25 & 98,75 & 99,25 & 99,20 \\
Duyarlılık & 99,00 & 100 & 100 & 100 & 99,00 & 99,60 \\
Özgüllük & 100 & 98,50 & 98,50 & 97,50 & 99,50 & 99,80 \\
Kesinlik & 100 & 98,52 & 98,52 & 97,56 & 99,50 & 98,82 \\
F1-skor & 99,50 & 99,26 & 99,25 & 98,77 & 99,25 & 99,20 \\
\hline
\end{tabular}

Tablo 1'de görüldüğü üzere ortalama \%99,20 oranında bir doğrulukla maskeli ve maskesiz yüzlerin doğru olarak sınıflandırılmıştır. Her bir sınıflandırma katı için elde edilen sınıflandırma doğruluk değerlerinin birbirine yakın olması, önerilen modelin veri setin bütün örnekleri için tutarlı bir performans sergilediğin göstergesidir. Maskeli yüzlere ilişkin örüntülerin ortalama \%99.6 olarak doğru sınıflandırılarak, modelin maskeli yüzleri tespitinde başarısını ortaya koymaktadır. Duyarlılık ve Özgüllük model metriklerinin her kat için birbirine yakın olması modelin herhangi bir sınıf için aşırı uyumlamaya gitmediğinin göstergesidir. Önerilen modelin öğrenmede iyi bir genelleştirme yapması ile yapay zekâ tabanlı tanı sistemlerinde elzem bir koşulun yerine getirildiği söylenebilir.

Model başarım metriklerine ilave olarak, önerilen modelin tüm sınıflandırma eşiklerinde performansını gösteren ROC eğrisi analizi de yapılmıştır. ROC eğrileri ile tüm eşikler için doğru pozitif oranı (TPR) ve yanlış pozitif oranının (FPR) birbirleriyle olan bağıntısı grafiksel olarak yorumlanabilir. ROC eğrileri dikkate alınarak, her bir kata ilișkin veri dağılımı için eğri altında kalan alan (AUC) değerleri hesaplanmıştır. Böylelikle, toplu bir 


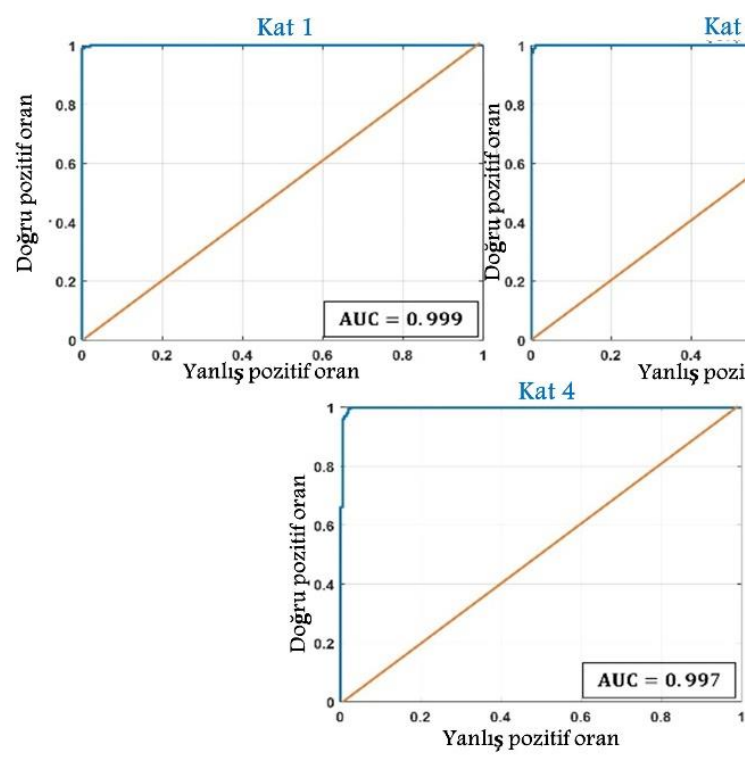

Kat 2
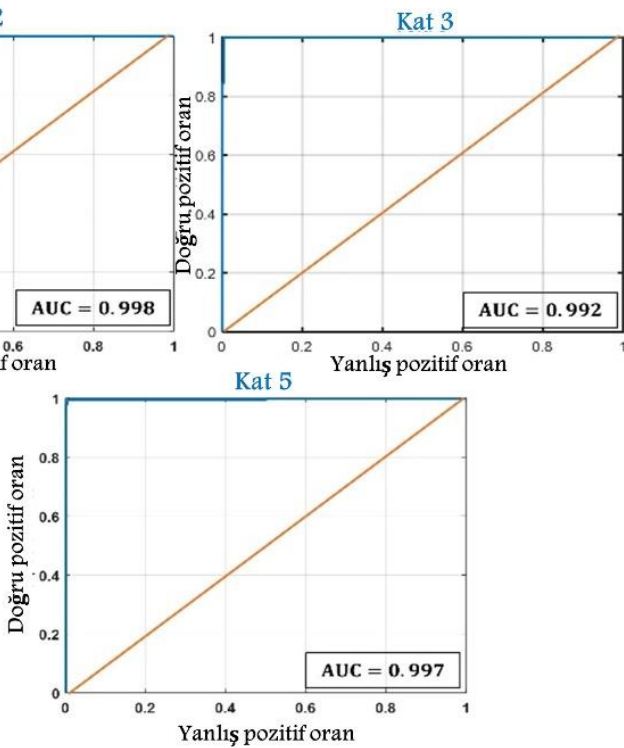

Şekil 7. Transfer öğrenimi yaklaşımına ilişkin ROC eğrileri ve AUC değerleri

performans ölçülmesi sağlanmaya çalışılmıştır. Transfer öğrenimi yaklaşımı tabanlı önerilen model için her bir sınıflandırma katı için elde edilen ROC eğrileri ve AUC değerleri Şekil 7'de gösterilmektedir.

Şekil 7'de gösterilen her bir sınıflandırma katı için ROC eğrileri ve AUC değerleri, önerilen modelin maskeli ve maskesiz yüzleri neredeyse kusursuz olarak ayırt edebildiğini göstermektedir. Transfer öğrenimi yaklaşımı ile önceden eğitilmiş ağırlıkların, probleme özgü kusursuz olarak adapte oldukları tespit edilmiştir.

Transfer öğrenimi yaklaşımının üstünlüğünü gözlemlemek adına önceden eğitilmemiş SqueezeNet modeli sil baştan eğitilerek, medikal maske tespitindeki performansı değerlendirmeye alınmıştır. Herhangi bir eğitilmiş parametre içermeyen SqueezeNet modelinin sil baştan eğitimi ile ölçülen model başarım metrikleri tablo 2'de verilmektedir. Sil baştan eğitilen mimari için belirlen başlangıç parametreleri ince ayar yapılan mimari ile aynı olarak seçilmiştir. Bu kapsamda, maksimum tekrar sayısı 50 olarak ayarlamıştır. ADAM aktivasyon fonksiyonu iyileştirici olarak kullanılmıştır. Başlangıç öğrenme katsayısı ise 0,0001 olarak ayarlanmış ve her bir iterasyondaki görüntü sayısı ise 64 olarak belirlenmiştir.

Tablo 2. Sil baştan eğitilen model ile elde edilen model başarım metrikleri

\begin{tabular}{lcccccc}
\hline$\%$ & Kat1 & Kat 2 & Kat 3 & Kat 4 & Kat 5 & Ortalama \\
\hline Doruluk & 92,75 & 96,25 & 94,50 & 95,00 & 95,25 & 94,75 \\
Duyarlılık & 92,50 & 95,50 & 98,50 & 99,50 & 94,50 & 96,10 \\
Özgüllük & 93,00 & 97,00 & 90,50 & 90,50 & 96,00 & 93,40 \\
Kesinlik & 92,96 & 96,25 & 91,20 & 91,28 & 95,94 & 93,67 \\
F1-skor & 92,73 & 96,22 & 94,71 & 95,22 & 95,21 & 94,82 \\
\hline
\end{tabular}

Tablo 2'de görüldüğü üzere sil baştan eğitilen aynı mimari ile ortalama \%94,75 oranında bir doğrulukta sınıflandırma performansı elde edilmiştir. Söz konusu performansın maskeli ve maskesiz yüzlerin tanısında, transfer öğrenimi yaklaşımın gerisinde kaldığı açıktır. Sil baştan eğitilen mimarinin maskeli yüzlere ilişkin örüntüleri ortalama \%96,1 oranında bir doğrulukta tespit ettiği gözlemlenmiştir. Duyarlılık ve özgüllük performansının bazı sinıflandırma katlarında birbirinden uzak olması, öğrenmede transfer öğrenimine kıyasla arzu edilen seviyede iyi bir genelleştirmenin yapılamadığının belirtisidir. Sil baştan eğitilen mimariye ilişkin model başarım metrikleri transfer öğrenimi yaklaşımı uygulanan model ile kıyaslandığında genel olarak sergilenen performansın düşük olduğu söylenebilir. Sil baştan eğitilen modele ilişkin ROC eğri analizi ise Şekil 8 'de verilmektedir.

Sil baştan eğitilen mimariye ilişkin her bir sınıflandırma katı için elde edilen ROC eğrileri ve AUC değerleri, önerilen modelin maskeli ve maskesiz yüzleri iyi bir şekilde ayırt edebildiğinin göstergesidir. Ancak, belirli sınıflandırma eşiklerinde sergilenen performansının transfer öğrenimi yaklaşımının gerisinde kaldığı açıktır. Dolayısıyla, büyük ölçekli görüntü kümeleri üzerinde önceden eğitime tabi tutulmuş optimize ağırlıkların kullanılması, model performansını olumlu etkilediği söylenebilir.

\section{TARTISMA}

Derin öğrenme yaklaşımı özellikle gerçek zamanlı uygulamalarda farklı alanlar için muazzam bir performans sergileme potansiyeline sahiptir. $\mathrm{Bu}$ potansiyellerden biri nesne tanıma problemidir. $\mathrm{Bu}$ alanda sergilenen etkinlikten esinlenerek COVID-19 salgını ile mücadelede geliştirilen bilgisayar destekli modellerde ESA algoritmaları ağırlığını ortaya koymaktadır. Derin öğrenme modelleri kullanılarak, COVID-19 ile mücadelede çoğunlukla hastalığın erken tanısı için modellerin geliştirildiği görülebilmektedir. Bu çalışmalarda radyografi yöntemi ile elde edilen görüntülerden COVID-19'un erken ve doğru tanısı hedeflenmiştir. Böylelikle, pandemi sürecinde hekimlere destek sağlayarak aşırı iş yükü hafifletilebilir. Ancak, COVID-19 salgının kalabalık ortamlarda ve yakın temaslarda yüksek bulaşıcılık karakterinde oluşu dikkate 


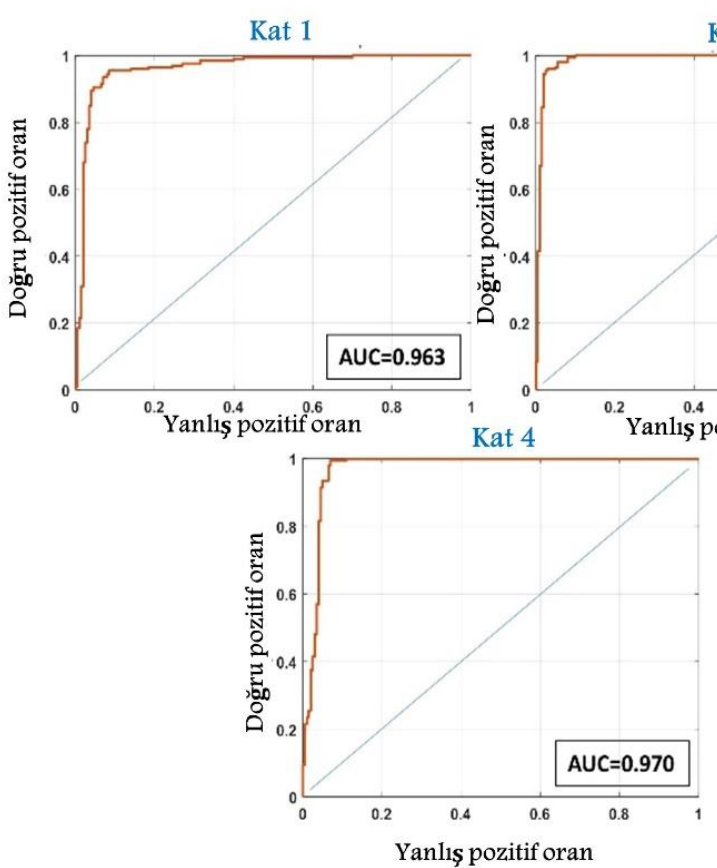

Şekil 8. Sil baştan eğitilen modele ilişkin ROC eğrileri ve AUC değerleri

alındığında, medikal maske tespiti için önerilen modellerin en az erken tanı sistemleri kadar önemli olduğu açıktır. $\mathrm{Bu}$ motivasyonla yola çıkarak, bu çalışmada kamusal alanda medikal maske kullanımın tespitinde başarılı bir model önerilmiştir.

Derin öğrenme tabanlı önerilen modellerde ağların eğitimi için çok sayıda örnek görüntü verilerinin kullanılması gerekir. Kısa sürede etkili çözümler sunan modellerin geliştirilmesi gerekliliği ve veri setlerin oluşturulmasında uygulanan prosedürler, sınırlı sürede büyük veri setlerinin oluşturulmasını olanaksız kılmaktadır. Dolayısıyla, literatürde geliştirilen modellerin sınırlı görüntü kümeleri üzerinde eğitilmeye çalışıldığ görülebilmektedir [10, 20]. Derin modellerin eğitimi için sınırlı görüntü sayısı, önerilen modellerin performansını olumsuz etkilemektedir. Bu çalışmada, görüntü sayısından kaynaklanan dezavantajın üstesinden transfer öğrenimi yaklaşımı ile gelinmiştir. Transfer öğrenimi yaklaşımı uygulanarak sınıflandırma doğruluğu $\% 4.45$ oranında artırılmıştır.

Transfer öğrenimi yaklaşımının küçük yapıdaki SqueeezeNet mimarisi üzerinde kullanılması ile literatürde mevcut olan ve başarılı çıktılar üreten modellerle paralel bir performans elde edilmiştir. $\mathrm{Bu}$ kapsamda, Khandelwal et al. [10] medikal maske kullanımına ilişkin ikili görüntü sınıflandırma problemi için bir derin öğrenme modeli önermişlerdir. Çalışmalarında, CCTV kameralarından kayıt edilen görüntülerden oluşturulan görüntü verisine MobileNet v2 modeli, uygulayarak AUC performansını 0,976 olarak elde etmişlerdir. Loey et al. [5] medikal maske tanımada derin öğrenme ve konvansiyonel yönteme dayanan bir hibrit model önermişlerdir. Çalışmalarında, Gerçek Dünya Maskeli Yüz Veri Kümesi (RMFD) kullanmışlardır. Toplamda 5000'i maskeli ve 5000'i maskesiz olmak üzere 10000 bin görüntü kullanılmıştır.
Kat 2
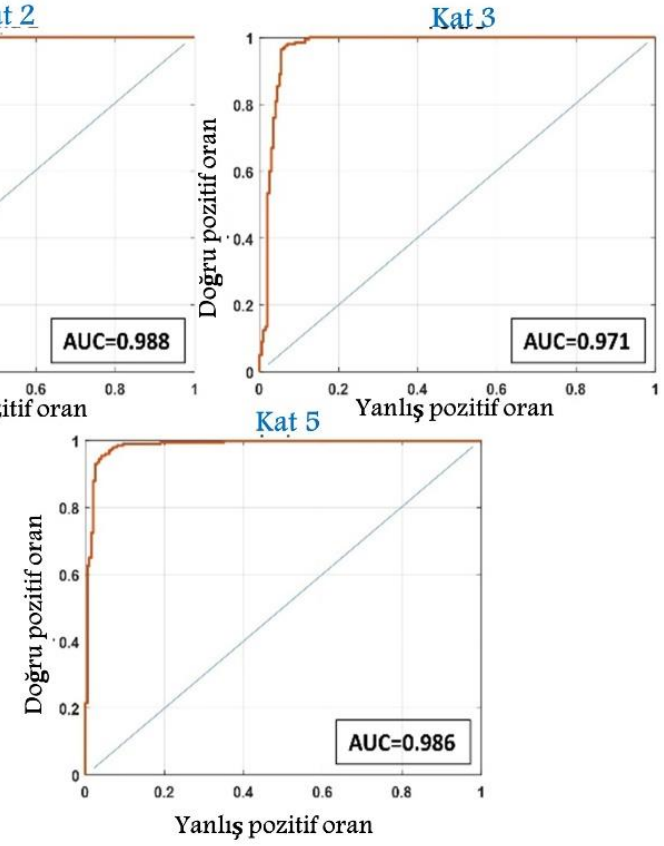

ResNet50 ve DVM algoritmasına dayanan hibrit yöntem ile \%99,64 oranında sınıflandırma doğruluğu elde etmişlerdir. Rao et al. [20] maske tespitinde her biri 100 filtreden oluşan iki evrişim katmanlı ESA modeli ile $\% 91,21$ oranında sinıflandırma doğruluğu elde edilmiştir. $\mathrm{Bu}$ çalışmada transfer öğrenimi yaklaşımı ile sınıflandırma \%99,72 olarak elde edilmiştir. Önerilen modelin gerçek zamanlı sistemlere güveli bir şekilde entegre edilebileceği göstermektedir.

\section{SONUÇ}

COVID-19 hastalığının başlıca bulaşma yollarının solunum damlacıkları ve fiziksel temas olduğu bilinmektedir. Medikal maske kullanımın salgınla mücadele en etkin yöntemlerden biri olduğu DSÖ tarafından ilan edilmiştir. Hastalığın yayılımını önlemek ve salgınla mücadele etmenin kapsamlı stratejilerinden biri olarak kamusal alanda medikal maske kullanımı birçok toplumda zorunlu kılınmıştır. Dolayısıyla, kamusal alanda medikal maske kullanımının otomatik olarak kontrolü, salgınla mücadelede önem arz etmektedir. Bu çalışmada, transfer öğrenimi yaklaşımı ile kamusal alandan alınan görüntülerden medikal maske kullanımının otomatik olarak tespit edilmesine ilişkin derin öğrenme tabanlı bir model önerilmiştir. Sınırlı sayıda eğitim verisinden kaynaklanan handikabın, transfer öğrenimi uygulanarak üstesinden gelinmiştir. Transfer öğrenimi yaklaşımı ile \%99,20 oranında sınıflandırma doğruluğu elde edilmiştir. Transfer öğrenimi uygulamadan önerilen ağın sil baştan eğitimi ile \%94,75 sınıflandırma doğruluğunda bir performans elde edilmiştir. Böylelikle, transfer öğrenimi yaklaşımının üstünlüğü elde edilen bulgularla kanıtlanmıştır.

Medikal maske kullanımına ilişkin yapılan çalışmalar için genel motivasyon, önerilen modellerin, kamu 
alanlarını gözetleyen kamera sistemlerine entegre edilebilir oluşudur. $\mathrm{Bu}$ çalışmada; daha az iletişim gereksinimi, daha küçük bant genişliği ve sınırlı depolama alanına sahip donanımlara entegre edilebilme avantajlarına sahip SqueezeNet mimarisi ile başarılı çıktıların üretilmesi, gerçek zamanlı uygulamalar için bir model geliştirildiğinin göstergesidir. İleride, bu çalışmada önerilen modelin donanımsal olarak uygulanması ile gerçek zamanlı kontrol sistemlerinin geliştirilmesi hedeflenmektedir.

\section{KAYNAKLAR}

[1] Toğaçar M, Ergen B, Cömert Z. COVID-19 detection using deep learning models to exploit Social Mimic Optimization and structured chest Xray images using fuzzy color and stacking approaches. Comput. Biol. Med. 2020;121:103805.

[2] Pereira RM, Bertolini D, Teixeira LO, Silla Jr CN, Costa YMG. Covid-19 identification in chest X-ray images on flat and hierarchical classification scenarios. Comput Methods Programs Biomed. 2020;94;105532.

[3] ICTV 2020 [internet]. [cited 14.02.2020]. Available from: https://talk.ictvonline.org/.

[4] WHO 2021 [internet]. [cited 30.05.2021]. Available from: https://www.who.int/emergencies/diseases/novelcoronavirus-2019/.

[5] Loey M, Monogaran G, Taha MHN, Khalifa NEM. A hybrid deep transfer learning model with machine learning methods for face mask detection in the era of the COVID-19 pandemic, Measurement. 2021;167: 108288.

[6] Butt C, Gill J, Chun D, Babu BA. Deep learning system to screen coronavirus disease 2019 pneumonia. Appl Intell. 2020;1-7.

[7] Ozturk T, Talo M, Yildirim EA, Baloglu UB, Yildirim O, Acharya UR. Automated detection of covid-19 cases using deep neural networks with X-ray images. Comput. Biol. Med. 2020;121:103792.

[8] Ucar F, Korkmaz D. COVIDiagnosis-Net: Deep Bayes-SqueezeNet based diagnosis of the coronavirus disease 2019 (COVID-19) from X-ray images. Med. Hypotheses. 2020;140: 109761.

[9] Batagelj B, Peer P, Štruc V, Dobrišek S. How to Correctly Detect Face-Masks for COVID-19 from Visual Information?. Appl. Sci. 2021;11:2070.

[10] Khandelwal P, Khandelwal A, Agarwal S. Using Computer Vision to enhance Safety of Workforce in Manufacturing in a Post COVID World. arXiv 2020, arXiv:2005.05287.

[11] Qin B, Li D. Identifying Facemask-wearing Condition Using Image Super-Resolution with Classification Network to Prevent COVID-19. Sensors. 2020;20:5236.

[12] HITL 2021 [internet]. [cited 02.04.2021]. Available from: https://humansintheloop.org/resources/datasets/med ical-mask-dataset/
[13] Zhang Q, Yang LT, Chen Z, Li P. A survey on deep learning for big data. Inform. Fus. 2019;42:146-157.

[14] Fayek HM, Lech M, Cavedon L. Evaluating deep learning architectures for speech emotion recognition. Neural Network. 2017;92:60-68.

[15] Alom MZ, Taha TM, Yakopcic C, Westberg S, Sidike P, Nasrin MS, et al. A state-of-the-art survey on deep learning theory and architectures. Electronics. 2019;8:292.

[16] Acharya UR, Oh SL, Hagiwara Y, Tan JH, Adeli H. Deep convolutional neural network for the automated detection and diagnosis of seizure using EEG signals, Comput. Biol. Med. 2018;100:270278.

[17] Iandola FN, Han S, Moskewicz MW, Ashraf K, Dally WJ, Keutzer K. SqueezeNet: AlexNet-Level Accuracy with 50x Fewer Parameters And $<0.5$ MB Model Size, arXiv preprint. 2016; arXiv:1602.07360.

[18] Minaee S, Kafieh R, Sonka M, Yazdani S, Jamalipour Soufi G. Deep-COVID: predicting COVID-19 from chest X-ray images using deep transfer learning, Med. Image Anal. 2020;65:101794.

[19] Xiao T, Liu L, Li K, Qin WJ, Yu SD, Li ZC. Comparison of transferred deep neural networks in ultrasonic breast masses discrimination, Biomed Res. Int. 2018;2018:4605191.

[20] Rao TS, Devi SA, Dileep P, Ram MS. A Novel Approach To Detect Face Mask To Control Covid Using Deep Learning, European Journal of Molecular \& Clinical Medicine. 2020;7(6):658668. 